\title{
Early Biochemical Alterations in Manganese Toxicity: Ameliorating Effects of Magnesium Nitrate and Vitamins
}

\author{
Shakeel ZAIDI ${ }^{*}$, Ashwin PATEL ${ }^{1}$, Nilesh MEHTA², Kanaiyalal PATEL ${ }^{1}$, \\ Ramnath TAKIAR ${ }^{3}$ and Habibullah SAIYED ${ }^{1}$
}

\author{
${ }^{1}$ National Institute of Occupational Health (I.C.M.R), Ahmedabad Gujarat, 380 016, India \\ ${ }^{2}$ Present address: Lab Corp. of America Inc, 13900 Park Centre Rd. Herndon, VA 20171, USA \\ ${ }^{3}$ Present address: National Cancer Registry Programmme (ICMR), 557 - 7th Main New B.E.L. Road, Bangalore \\ 560094 , India
}

Received November 12, 2004 and accepted June 29, 2005

\begin{abstract}
Manganese-induced early biochemical changes and effects of supplementation of magnesium nitrate $\left(\mathrm{Mg}\left(\mathrm{NO}_{3}\right)_{2}\right)$ and antioxidant vitamins $(\mathrm{A}, \mathrm{C}, \mathrm{D}$ and $\mathrm{E}$ ) were studied in rats intoxicated with manganese. Significant elevation in the level of chlorides in plasma, erythrocytes, liver and cerebellum, and a decrease in plasma inorganic phosphate (pi) with an increase in liver pi were observed in animals exposed to manganese as compared to controls. The level of erythrocyteacid labile phosphate (ALP), nicotinamide adeninedinucleotide $\left(\mathrm{NAD}^{+}\right)$and plasma sialic acid $(\mathrm{N}$ acetylneuraminic acid, NANA) also increased significantly. Elevated levels of chlorides in plasma, erythrocytes and cerebellum reversed to normal control values whereas liver chlorides restored partially by the supplementation of $\mathrm{Mg}\left(\mathrm{NO}_{3}\right)_{2}$. Vitamins supplementation was effective to reverse chlorides level in erythrocytes, liver and cerebellum. Decreased level of pi in plasma and the highly elevated level of erythrocyte ALP were also recovered in animals received $\mathrm{Mg}\left(\mathrm{NO}_{3}\right)_{2}$ in addition to $\mathrm{MnSO}_{4}$. However, such effect of $\mathrm{Mg}\left(\mathrm{NO}_{3}\right)_{2}$ was not seen in lowering the elevated level of NANA that restored by the administration of vitamins. Thus, the early alterations in plasma levels of chlorides, pi, and NANA and erythrocyte-ALP seem to be an indicative of early manganese toxicity while $\mathrm{Mg}\left(\mathrm{NO}_{3}\right)_{2}$ and vitamins supplementation appear to provide, at least in part, protection against manganese toxicity.
\end{abstract}

Key words: Biochemical alterations, Manganese toxicity, Ameliorating effects, Magnesium nitrate, Antioxidant vitamins

\section{Introduction}

Over exposure to manganese is well known to cause derangement in the metabolism of various enzymes and other biomolecules, as reviewed ${ }^{1-3)}$ earlier, and some of these alterations may further advance to contribute and/or culminate in a Parkinsonism-like disease known as manganism $^{4,5)}$. Owing to the facts that chronic manganese

*To whom correspondence should be addressed. poisoning (manganism), with few exceptions ${ }^{6}$ ) is almost incurable and the biochemical changes precede structural damage, much attention has recently been paid to those intermediate biochemical changes and/or physiological endpoints $^{7,8)}$ that probably occur after exposure or possibly before the appearance of the illness. Data available in these lines are very limited and indicators that could consistently be used to detect early manganese poisoning are currently lacking. However, some biochemical changes in manganese toxicity have been found useful in assessing early manganese 
poisoning. Studies conducted in experimental animals, 10) and suspected cases of manganese poisoning ${ }^{11)}$ revealed that serum calcium, inorganic phosphate and adenosine deaminase are some of the biochemical changes that could possibly be used in the early detection of manganese poisoning. The elevated level of serum prolactin ${ }^{12)}$ and the increased activity of lymphocytes manganese-dependent superoxide dismutase (MnSOD) in conjugation with higher concentration of blood manganese ${ }^{13)}$ have been suggested as useful peripheral biomarkers of manganese exposure. But their potential usefulness as sensitive biomarkers is debatable ${ }^{14,15}$. Studies reported by us earlier indicated the usefulness of serum chloride and sialic acid ${ }^{16,17)}$ and blood and urinary nicotinamide nucleotides ${ }^{18)}$ in the early detection of manganese toxicity.

Therapeutic methods for reducing manganese poisoning are also not satisfactory and no specific antidote to cure manganese poisoning is available till date. There are indications that manganese excess induces hypomagnesia ${ }^{11}$. In one of our recent studies conducted on manganese-miners, significant low level of magnesium and inorganic phosphate in plasma were observed (Zaidi et al., unpublished data). Reports are also available which indicate that magnesium supplementation as a therapeutic drug improves cellular abnormalities and neurological outcome ${ }^{19)}$, however, its efficacy in reducing manganese poisoning that is also causing degenerative and neurological disorders has not been yet elucidated. It is also known that manganese toxicity effects progress by declining potential of antioxidant system by reducing antioxidant enzymes and vitamins. Parenti et al. ${ }^{20)}$ demonstrated that addition of antioxidant enzymes prevented the death of cultured fibroblast induced by manganese while vitamin $E$ helps reduce striatal loss of dopamine in substantianigra. Beneficial role of antioxidant enzymes and vitamins in improving cellular damage caused by various toxins are being increasingly clear, however, their role in improving manganese toxicity remains unclear.

It seems a great cause of concern for developing new methods for early detection and alleviation of manganese poisoning. Keeping this in view, and in continuation to our previous studies on manganese toxicity ${ }^{16-18)}$, the present study was designed to examine some of the very early biochemical changes in rats exposed to manganese at the reversible stages of manganese toxicity. Levels of chlorides, inorganic phosphate (pi), and sialic acid ( $\mathrm{N}$-acetylneuraminic acid, NANA) and nicotinamide adenine dinucleotide $\left(\mathrm{NAD}^{+}\right)$were studied in detail in different tissues and the efficacy of magnesium nitrate $\left(\mathrm{Mg}\left(\mathrm{NO}_{3}\right)_{2}\right)$ and fat-soluble vitamins (A, $\mathrm{D}$, and $\mathrm{E}$ ) and ascorbic acid (vitamin $\mathrm{C}$ ) was evaluated by studying the reversal of some biochemical parameters found altered in early manganese toxicity.

\section{Materials and Methods}

\section{Chemicals}

Nicotinamide adenine dinucleotide $\left(\mathrm{NAD}^{+}\right)$was obtained from Loba Chemie (India). Vitamins (A, D, and E), as a commercial preparation, Bejectal $^{\circledR}$, was purchased from Abbott Laboratory, India. Ascorbic acid (vitamin C) was obtained from Aldrich, USA. All the other reagents and chemicals used in the present study were of high analytical purity grade.

\section{Treatment of Animals}

Sixty male albino rats (CF strain) weighing about $240 \pm$ $5 \mathrm{~g}$ were divided in to six groups consisting of 10 animals each. The animals were maintained on standard laboratory diet and water ad-libtum. They were treated as follows.

Group 1 Injected with $\mathrm{Na}_{2} \mathrm{SO}_{4}(16.6 \mathrm{mg} / \mathrm{kg}$ bw) in distilled water, adjusted to $\mathrm{pH}$ 7.4.

Group 2 Injected with $6 \mathrm{mg} \mathrm{Mn}{ }^{2+} / \mathrm{kg}$ bw as $\mathrm{MnSO}_{4}$.

Group 3 Injected with $1.3 \mathrm{mg} \mathrm{Mg}^{2+} / \mathrm{kg}$ bw as $\mathrm{Mg}\left(\mathrm{NO}_{3}\right)_{2}$.

Group 4 Received both $\mathrm{MnSO}_{4}$ and $\mathrm{Mg}\left(\mathrm{NO}_{3}\right)_{2}(6 \mathrm{mg}$ $\mathrm{Mn}^{2+}+1.3 \mathrm{mg} \mathrm{Mg}^{2+} / \mathrm{kg}$ bw), simultaneously.

Group 5 Injected with vitamin A, $100 \mathrm{IU}+$ vitamin D, $10 \mathrm{IU}$ and vitamin $\mathrm{E}, 50 \mu \mathrm{g}+$ Vitamin $\mathrm{C}, 5 \mathrm{mg}$ in distilled water, (in $0.1 \mathrm{ml} /$ animal daily).

Group 6 Vitamins as in group $5+6 \mathrm{mg} \mathrm{Mn}^{2+} / \mathrm{kg}$ bw.

All the solutions were prepared biweekly, refrigerated at $4^{\circ} \mathrm{C}$ and brought to room temperature before the administration. Solutions were injected intraperitoneally (ip) in $0.2 \mathrm{ml} /$ animal daily (vitamins in $0.1 \mathrm{ml}$ ) to each group of animals and the treatment was continued for four weeks. Animals were fasted for $18 \mathrm{~h}$ and sacrificed under ether anesthesia. Blood was collected in to heparinised tubes by cardiac puncture and centrifuged at $3,500 \times \mathrm{g}$ to separate plasma and erythrocytes. Liver and cerebellum were dissected out, washed, and frozen in dry ice. Plasma and other tissues were processed within week for various biochemical investigations.

\section{Biochemical estimation}

All the measurements were done at room temperature, (about $28^{\circ} \mathrm{C}$ ) unless otherwise mentioned. Chlorides in plasma and other tissues were estimated by the titration method according to the procedure described earlier ${ }^{21)}$. Inorganic phosphate in plasma, erythrocytes and liver, and 
erythrocyte-acid labile phosphate (heated in $1 \mathrm{~N} \mathrm{H}_{2} \mathrm{SO}_{4}$ for $15 \mathrm{~min}$ at $80^{\circ} \mathrm{C}$ ) were measured ${ }^{22}$. Nicotinamide adenine dinucleotide $\left(\mathrm{NAD}^{+}\right.$, oxidized form) was estimated by the procedure of Ciotti and Kaplann ${ }^{23)}$. Plasma sialic acid (NANA) was determined from $0.4 \mathrm{~N}$ perchloric acid filtrates by the thiobarbituric acid method $\left.{ }^{24}\right)$ using dimethylsulfoxide. Manganese content in liver was estimated by Atomic absorption spectrometer using Perkin-Elmer (Model 3100, double beam).

\section{Statistical analysis}

Student - $t$ test was applied to see the significant difference in the tissue content of manganese in liver of control and manganese exposed group (group 1 and 2). To test the possible significant differences among all the six groups, analysis of variance (ANOVA) was applied. If 'between group differences' found significant, multiple range-test was applied. The groups, showing insignificant difference were kept under same parenthesis, while those differing significantly from each other, are shown in separate brackets. The significance was tested at $5 \%$ level.

\section{Results}

Rats exposed to manganese showed significant $(\mathrm{p}<0.01)$ higher accumulation of manganese in liver as compared to control animals (Fig. 1). All the animals survived during the course of this study. The effects of exposure to manganese on the various biochemical parameters and the ameliorating of $\mathrm{Mg}\left(\mathrm{NO}_{3}\right)_{2}$ and vitamins are summarized in Table 1. Results of ANOVA analysis indicated that the levels of chlorides in plasma, erythrocytes, liver and cerebellum in manganeseexposed animals (group 2) were found significantly elevated as compared to the controls (group 1) (Table 1, ANOVAtest). The levels of chlorides in control group (group 1) and respective controls (group 3 and 5) differ insignificantly. Such values are comparable with the values obtained for animals of group 4 administered with $\mathrm{MnSO}_{4}$ and $\mathrm{Mg}\left(\mathrm{NO}_{3}\right)_{2}$, simultaneously. This indicates the reversibility of manganese toxicity as the elevated levels of chlorides in plasma, erythrocytes, and cerebellum (group 2) reversed nearly to the control values as shown in (group 4). However, such effect was poorly observed in liver where the elevated level of chlorides reversed partially. Vitamins supplementation was effective in reversing chlorides level in erythrocytes and cerebellum while plasma chlorides progressed further significantly (group 2 and 6). Thus, both $\mathrm{Mg}\left(\mathrm{NO}_{3}\right)_{2}$ and vitamins were effective in ameliorating chlorides levels in erythrocytes and cerebellum.

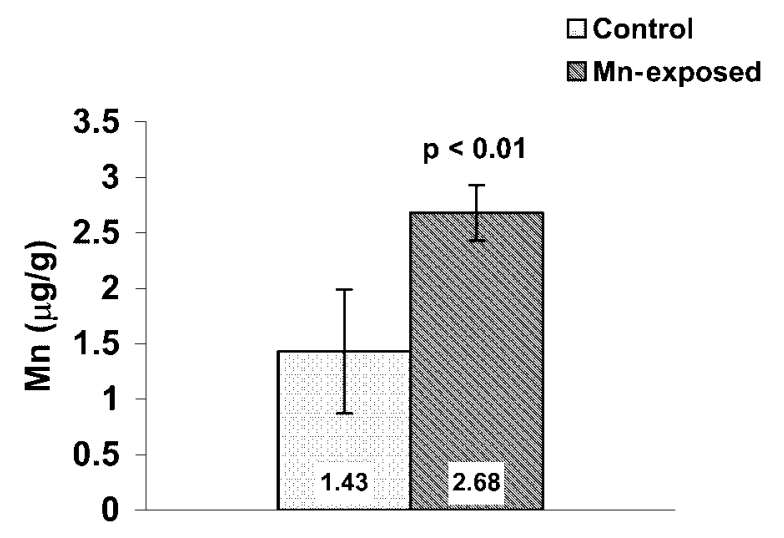

Fig. 1. Levels of manganese in rat liver.

A significant decrease in plasma inorganic phosphate (pi) and a marked increase in liver pi were observed in animals exposed to manganese (group 2) as compared to control (group1). Erythrocytes pi was not found significantly changed. Reduced level of plasma pi almost reversed to its control value while the elevated level of liver pi restored partially. The reduced plasma pi is in accordance with our recent findings observed in manganese miners (Zaidi et al., unpublished data).

Erythrocyte values for acid labile phosphate (ALP), measured indirectly as ATP increased by about $180 \%$ of control in manganese experimental group (Group 2) and the highly elevated level completely reversed in animals of group 4. However, vitamins supplementation (group 6) failed to reverse the elevated level of ALP observed in group 2. The elevated level of ALP (6.7 mg\%, group 2) was further advanced significantly (9.64 mg\%, group 6) in animals supplemented with vitamins. Erythrocytes $\mathrm{NAD}^{+}$was significantly elevated in all the groups (group 2 to 6 ) when compared with control group (group 2). This is in accordance with our previous findings ${ }^{18}$. Both $\mathrm{Mg}\left(\mathrm{NO}_{3}\right)_{2}$ and vitamins were found ineffective to reverse the elevated level of $\mathrm{NAD}^{+}$.

Plasma (NANA) increased by 1.58 fold over control (group 1) in rats exposed to manganese (Group 2) and the elevated level of NANA was brought back to normal values by vitamins supplement (group 6). However, magnesium nitrate supplementation failed to reverse the elevated level of NANA, and it was rather advanced to a high significant level (group 4). The plasma PCA soluble NANA was further fractionated with trichloroacetic acid (TCA) and approximately 3 -fold increase in the level of NANA was obtained in manganese exposed rats as compared to controls $(1.90 \pm 0.21$ vs $5.66 \pm 0.5 \mathrm{mg} \%)$. 
Table 1. Levels of some biochemical parameters in rats exposed to manganese: Effects of supplementation of magnesium nitrate and vitamins

\begin{tabular}{|c|c|c|c|c|c|c|c|c|}
\hline Parameter & $\begin{array}{l}\text { Group-1 } \\
\left(\mathrm{Na}_{2} \mathrm{SO}_{4}\right)\end{array}$ & $\begin{array}{l}\text { Group-2 } \\
\left(\mathrm{MnSO}_{4}\right)\end{array}$ & $\begin{array}{c}\text { Group-3 } \\
\mathrm{Mg}\left(\mathrm{NO}_{3}\right)_{2}\end{array}$ & $\begin{array}{c}\text { Group-4 } \\
\mathrm{MnSO}_{4}+ \\
\mathrm{Mg}\left(\mathrm{NO}_{3}\right)_{2}\end{array}$ & $\begin{array}{c}\text { Group-5 } \\
\text { Vitamins } \\
(\mathrm{A}+\mathrm{C}+\mathrm{D}+\mathrm{E})\end{array}$ & $\begin{array}{c}\text { Group-6 } \\
\mathrm{MnSO}_{4}+ \\
(\mathrm{A}+\mathrm{C}+\mathrm{D}+\mathrm{E})\end{array}$ & $\begin{array}{l}\text { ANOVA } \\
\text { (Multiple } \\
\text { range test) }\end{array}$ & $\begin{array}{l}\text { Substance } \\
\text { effective in } \\
\text { reversing } \\
\text { toxic effects }\end{array}$ \\
\hline \multicolumn{9}{|l|}{ 1. Chlorides } \\
\hline a. Plasma, $\mathrm{mg} \%$ & $336.5 \pm 17.0$ & $378.8 \pm 7.0$ & $346.0 \pm 12.0$ & $330.0 \pm 6.0$ & $344.0 \pm 10.5$ & $383.1 \pm 8.5$ & $(1,3,4,5)(2,6)$ & $\mathrm{Mg}\left(\mathrm{NO}_{3}\right)_{2}$ \\
\hline b. Erythrocyte $(\mathrm{mg} / 100 \mathrm{ml})$ & $239.0 \pm 8.0$ & $320.0 \pm 4.30$ & $193.0 \pm 4.00$ & $200.0 \pm 25.0$ & $198.0 \pm 19.0$ & $244.0 \pm 6.0$ & $(1,6)(2)(3,5,4)$ & Both \\
\hline c. Liver (mg/g) & $1.70 \pm 0.024$ & $1.829 \pm 0.027$ & $1.753 \pm 0.021$ & $1.759 \pm 0.021$ & $1.70 \pm 0.057$ & $1.806 \pm 0.021$ & $(1,5)(3,4)(6,2)$ & $\mathrm{Mg}\left(\mathrm{NO}_{3}\right)_{2}$ \\
\hline d. Cerebellum (mg/g) & $1.650 \pm 0.013$ & $2.111 \pm 0.014$ & $1.753 \pm 0.015$ & $1.605 \pm 0.028$ & $1.556 \pm 0.054$ & $1.679 \pm 0.021$ & $(1,4,6)(2)(5)$ & Both \\
\hline \multicolumn{9}{|l|}{ 2. Phosphate (inorganic) } \\
\hline a. Plasma mg\% & $9.02 \pm 0.32$ & $6.96 \pm 0.038$ & $7.56 \pm 0.130$ & $9.24 \pm 0.14$ & nd & nd & $(1,4)(2,3)$ & $\mathrm{Mg}\left(\mathrm{NO}_{3}\right)_{2}$ \\
\hline b. Erythrocyte $(\mathrm{mg} / 100 \mathrm{ml})$ & $7.10 \pm 1.00$ & $7.00 \pm 1.50$ & $6.31 \pm 0.120$ & $5.63 \pm 1.40$ & nd & nd & $(1,2)(3)(4)$ & $\mathrm{Mg}\left(\mathrm{NO}_{3}\right)_{2}$ \\
\hline c. Liver $(\mathrm{mg} / \mathrm{g})$ & $0.456 \pm 0.027$ & $0.642 \pm 0.025$ & $0.437 \pm 0.031$ & $0.57 \pm 0.02$ & nd & nd & $(1,3)(2,4)$ & $\mathrm{Mg}\left(\mathrm{NO}_{3}\right)_{2}$ \\
\hline \multicolumn{9}{|l|}{ 3. ALP } \\
\hline Erythrocyte $(\mathrm{mg} / 100 \mathrm{ml})$ & $3.714 \pm 0.740$ & $6.70 \pm 0.72$ & $5.84 \pm 2.850$ & $3.790 \pm 0.940$ & $5.09 \pm 6.70$ & $9.64 \pm 7.20$ & $(1,4)(2)(3,5)(6)$ & $\mathrm{Mg}\left(\mathrm{NO}_{3}\right)_{2}$ \\
\hline \multicolumn{9}{|l|}{ 4. NAD } \\
\hline Erythrocyte $(\mathrm{mg} / 100 \mathrm{ml})$ & $13.30 \pm 1.10$ & $17.10 \pm 1.00$ & $24.20 \pm 1.00$ & $22.50 \pm 3.00$ & $18.10 \pm 2.0$ & $26.2 \pm 2.10$ & (1) (2,5) (3) (4) (6) & None \\
\hline \multicolumn{9}{|l|}{ 5. Plasma Salic acid (NANA) } \\
\hline 1. PCA-Soluble-(mg\%) & $10.4 \pm 1.2$ & $16.5 \pm 1.50$ & $8.90 \pm 0.80$ & $22.90 \pm 5.50$ & $5.70 \pm 0.50$ & $10.80 \pm 1.80$ & $(1,6)(2)(3)(4)(5)$ & $\begin{array}{l}\text { Vitamins } \\
(A+C+D+E)\end{array}$ \\
\hline $\begin{array}{l}\text { 2. PCA-Soluble-TCA } \\
\text { insoluble ( } \mathrm{mg} \%)\end{array}$ & $1.90 \pm 0.21$ & $5.66 \pm 0.50$ & $3.67 \pm 0.42$ & $13.21 \pm 1.90$ & $2.35 \pm 0.34$ & $5.66 \pm 0.80$ & $(2,6)(1)(3)(4)(5)$ & None \\
\hline
\end{tabular}

Each group contains 10 animals, values are expressed as Mean \pm S.E; ANOVA: analysis of variance (significant level tested at 5\%), pi: inorganic phosphate, ALP: acid labile phosphate; NAD+: nicotinamide adenine dinucleotide, oxidized form; NANA: N-acetyl neuraminic acid, nd: not done.

\section{Discussion}

Detection of manganese toxicity at reversible stages is of great value as such approaches might provide early opportunities to reduce the long-term outcome of the diseases and suggest the need to apply intervention measures ${ }^{7,8)}$. In the present investigation, early significant alterations in some of the biochemical parameters under the influence of manganese toxicity and their reversal by $\mathrm{Mg}\left(\mathrm{NO}_{3}\right)_{2}$ and vitamins $(\mathrm{A}+\mathrm{C}+\mathrm{D}+\mathrm{E})$ might provide useful information about the detection and alleviation of manganese toxicity, respectively. A consistent elevation in the level of chlorides in plasma and other different tissues is in accordance of our previous studies ${ }^{16,17)}$. It might be helpful in the early detection of manganese toxicity. Levels of chlorides and inorganic phosphate which have been found altered in the present investigation might influence manganese toxicity as chloride activity is linked to control the activity of $\gamma$-aminobutyric acid (GABA) ${ }^{25)}$ by altering chloride conductance across the GABA-gated chloride channel while pool of inorganic phosphate can affect energy production by causing mitochondrial dysfunction ${ }^{26}$. Thus, alteration in the level of chlorides or its transport may result in some pathological conditions of the nervous system as marked swelling of astrocytes after ischemia, hypoxia or trauma seems to be related to chloride transport ${ }^{27}$. As the elevated levels of chlorides were reversed in plasma, erythrocytes, liver and cerebellum, supplementation of $\mathrm{Mg}\left(\mathrm{NO}_{3}\right)_{2}$ and vitamins seems to provide protection, at least in part, against the diseases caused by malfunctioning of chloride metabolism.

The mechanism of impairment of various anions, cations and other metabolites in manganese toxicity has been poorly understood. The decreased levels of chloride observed in the erythrocytes might be due to perturbation of the activity of anion exchange protein commonly known as Band III protein. It is not yet clear whether the chloride-bicarbonate exchange is modulated by external exposure or the protein is intrinsically modified by covalent changes like phosphorylation etc. Thus, the decrease in chlorides and phosphates in plasma or increase in erythrocytes ALP in manganese toxicity as compared to controls might be due to variance in interaction among magnesium, manganese or other biomolecules. The condition of hypercalcaemia and hypophosphataemia in rabbits exposed to manganese has also been noted earlier ${ }^{10)}$. These authors suggested several reasons for hypophosphataemia that include interferences at gastrointestinal absorption of phosphates by certain metals or increased phosphate diuresis. The decrease in plasma 
inorganic phosphate is also in accordance with our recent observations in manganese miners (Zaidi et al., unpublished data).

PCA-soluble fraction with 1.58 fold increase in sialic acid is also a possible indicator of early manganese toxicity and these results substantiate our earlier findings ${ }^{16}$. Though, a three-fold increase in NANA levels in PCA-soluble TCAinsoluble fraction was obtained but the enzyme inhibition was not evidenced in this group. As evidenced from Table 1 , vitamins inhibition effect restored the elevated level of sialic acid from 16.5 to 10.8 , nearly to the normal control values of 10.4. Such effect was not seen in PCA-soluble TCA-insoluble fraction where the elevated level of sialic acid remained unchanged (i.e 5.66 vs 5.66; group 2 and group 6).

The antagonistic action of $\operatorname{Mg}\left(\mathrm{NO}_{3}\right)_{2}$ appears to be double fold, as nitrates are known to replace chlorides even in brain ${ }^{28)}$ while $\mathrm{Mg}^{+2}$ is exchanged with $\mathrm{Mn}^{+2}$ in many of the biochemical reactions, particularly where ATP metabolism is involved ${ }^{29}$. Several of the manganese-toxicity enhancing factors (Table 1) such as elevated levels of manganese in liver (Fig. 1) and the altered levels of chlorides, pi, ALP and NANA observed in this study appeared to be controlled, at least in part by the administration of $\mathrm{Mg}\left(\mathrm{NO}_{3}\right)_{2}$ and vitamins. The mechanism of reversal of these biochemical parameters (Table1) is still to be understood. As reported ${ }^{30)}$ earlier that metal ions commonly substitute for others of same size and charge, and since $\mathrm{Mg}^{2+}$ and $\mathrm{Mn}^{2+}$ both have almost similar size and charge, substitution of more toxic metal $\left(\mathrm{Mn}^{2+}\right)$ with less toxic metal $\left(\mathrm{Mg}^{2+}\right)$ is possible and this could provide a mean to reduce manganese toxicity, as observed in our present findings. Besides it, the multiple role performed by magnesium, in general, directly or indirectly in the physiology of cellular functions such as it improves lipid peroxidation and carbohydrate metabolism, regulates vitamin supply and involves in ATP metabolism and its lower toxicity than manganese appears to play important role in reducing manganese toxicity. The individual efficacy of each vitamin could not be elucidated in this study as a mixture of these vitamins was administered. Synergistic application of $\mathrm{Mg}\left(\mathrm{NO}_{3}\right)_{2}$ and vitamins deserve further evaluation.

\section{Conclusion}

This study suggests that the early alterations in the levels of chlorides and other biochemical parameters are suggestive of very early phase of manganese toxicity. Most of these altered biochemical parameters are reversible at this stage as the supplementation of $\mathrm{Mg}\left(\mathrm{NO}_{3}\right)_{2}$ and vitamins $(\mathrm{A}+\mathrm{C}+\mathrm{D}+\mathrm{E})$ appeared to provide protection, at least in part, against manganese toxicity.

\section{Acknowledgements}

Authors are thankful to A. Kumar, in-charge of animal house, National Institute of Occupational Health, Ahmedabad for maintaining the animals throughout the studies. Technical assistance rendered by S. J Gandhi in the preparation of this manuscript is acknowledged.

\section{References}

1) World Health Organization (1981) Environmental Health Criteria-No. 17, Manganese. WHO, Geneva.

2) Brenneman KA, Cattley RC, Ali SF, Dorman DC (1999) Manganese-induced developmental neurotoxicity in the $\mathrm{CD}$ rat: Is oxidative damage a mechanism of action? In: Manganese: Are there effects from long-term, lowlevel exposure? Neurotoxicology ${ }^{\circledast}$, Vol. 20. eds. by Cranmer J, Mergler D, Williams-Johnson M, 477-87, INTOX Press, Inc, USA.

3) Agency for Toxic Substances and Disease Registry, Tox Profiles (ATSDR) (2002) Toxicological Profile for Manganese and Compounds. U.S. Department of Health and Human Services Public Health Service, Division of Toxicology/Toxicology Information Branch, Atlanta, Georgia.

4) Calne DB, Chu NS, Huang CC, Lu Cs, Olanow W (1994) Manganism and Parkinson's: similarities and differences. Neurology 44, 1583-6.

5) Levy BS, Nassetta WJ (2003) Neurologic effects of manganese in humans; a review. Int J Occup Environ Health 9, 153-63.

6) Shuquin KY, Haishang D, Peiyi Xie, Wanda Hu (1992) A report of two cases of chronic serious manganese poisoning treated with sodium para-aminosalicylic acid. $\mathrm{Br} \mathrm{J}$ of Indus Med 49, 66-9.

7) Mutti A(1995) Use of intermediate end-points to prevent long-term outcomes. Tox Lett 77, 121-5.

8) Silbergeld EK (1993) Neurochemical approaches to developing biochemical markers of neurotoxicity: review of current status and evaluation of future prospects. Env Res 63, 272-86.

9) Mustafa SJ, Chandra SV (1972) Adenosine deaminase and protein pattern in serum and cerebrospinal fluid in experimental manganese encephalopathy. Arch Toxikol 28, 279-85. 
10) Chandra SV, Imam Z, Nagar N (1973) Significance of serum calcium, inorganic phosphates and alkaline phosphatase in experimental manganese toxicity. Ind Health 11, 43-7.

11) Chandra SV, Seth PK, Mankeshwar JK (1974) Manganese poisoning: clinical and biochemical observations. Environ Health 7, 374-80.

12) Smargiassi A, Mutti A (1999) Peripheral biomarkers and exposure to manganese. In: Manganese: Are there effects from long term, low-level exposure? eds. by Cranmer J, Mergler D, Williams-Johnson M, 401-6, INTOX Press Inc., USA.

13) Davis CD, Greger JL (1992) Longitudinal changes of manganese-dependent super oxide dismutase and other indexes of manganese and iron status in women. Am J Clin Nutr 55, 747-52.

14) Roels HA, Ghyselen P, Buchet JP, Ceulemans E, Lauwerys RR (1992) Assessment of the permissible exposure level to manganese in workers exposed to manganese dioxide dust. Br J Indus Med 49, 25-34.

15) Greger JL (1999) Nutrition versus toxicology of manganese in humans: evaluation of potential biomarkers. Neurotoxicology 20, 205-12.

16) Sarma TJ, Patel AB (1985) Experimental studies on manganese toxicity: neurochemical studies. Biol Memoirs $^{\mathrm{c}}$ 11, 82-7.

17) Patel AB, Bhatt HV (1989) Influence of trace metals on serum total sialic acids and perchloric acid- soluble proteins and sialic acids in mice. J Appl Toxicol 9, 678.

18) Patel AB, Pandya AA (1994) Effects of chronic manganese poisoning toxicity on tissue levels and urinary excretion of nicotinamide nucleotides in rats. Hum Exp Toxicol 13, 307-9.

19) Fenlinger M (1990) Therapy with magnesium salt in neurological disorders, a critical appraisal. Magnes Bulletin 12, 35-42.
20) Parenti M, Rusconi L, Cappabiaanca V, Parati EA Groppetti (1988) A Role of dopamine in manganese neurotoxicity. Brain Res 473, 236-40.

21) Shales $O$ (1953) Standard methods of clinical chemistry, vol. 1. ed. by Reiver M, 37, Academic Press, New York.

22) Fiske $\mathrm{CH}$, Subbarao $Y$ (1925) The colorimetric determination of phosphorous. J Biol Chem 66, 375400.

23) Ciotti MN, Kaplan NO (1957) Procedure for determination of pyridine nucleotide. In: Methods in Enzymology, vol. III. eds. by Colowick SP, Kaplan NO, 855, Acad Press, New York.

24) Skoza L, Mohos S (1976) Stable thiobarbituric acid chromatophore with dimethylsulphoxide: application to sialic acid assay in analytical de-O-acetylation. Biochem J 159, 457-62.

25) Allan AM, Harris RA (1986) $\gamma$-aminobutyric acid agonist and antagonists alter chloride flux across brain membranes. Mol Pharmacol 29, 497-505.

26) Klivenyi P, St Clair D, Wermer M, Yen HC, Oberley T, Yang L, Flint Beal M (1998) Manganese superoxidedismutase over expression attenuates MPTP toxicity. Neurobiol Dis 5, 253-8.

27) Tower DB (1979) Effect of ischemia or tissue hypoxia on the neuron. Adv Neurol 25, 39.

28) Bradbury M, ed. (1979) The concept of a blood—brain barrier. John Wiley and Sons, New York.

29) Mahler HR (1961) Interrelationship with enzymes mineral metabolism, an advanced treatise, vol. 1, part B. eds. by Comar CL, Bronner F, 773-80, Acad Press, New York.

30) Smith RA, Latchney LR, Senior AE (1985) Tight divalent metal binding to Escherichia Coli F1adenosinetriphosphatase. Complete substitution of intrinsic magnesium by manganese or cobalt and studies of metal binding sites. Biochemistry 24, 4490-4504. 